\title{
OJS

\section{NA ESCOLA, NEM TODOS OS GATOS SÃO PARDOS: ARMANDO UMA PERSPECTIVA PARA VER AS ARTES DE ENSINAR GEOGRAFIAS}

\author{
Mariana Mizael Pinheiro da Silva ${ }^{1}, E_{\text {Everardo Paiva de Andrade }}^{2}$
}

\begin{abstract}
${ }^{1}$ Doutoranda no Programa de Pós-Graduação em Educação na Universidade Federal Fluminense (UFF) e professora na rede municipal de ensino de Saquarema e de Maricá. E-mail: mari.mizael@ hotmail.com ORCID: 0000-0001-82219134

2 Professor da Universidade Federal Fluminense (UFF), do Programa de Pós-Graduação da Faculdade de Educação e do Profhistória. E-mail: everardo_andrade @uol.com.br ORCID: 0000-0003-0157-5650
\end{abstract}

Artigo recebido em 08/01/2021 e aceito em 05/03/2021

RESUMO: Como jogam os professores no terreno dos parâmetros e bases curriculares? Como lidam com a precarização do trabalho docente? Como enfrentar essas questões, porém sem romantizar as opressões? Por outro lado, como considerar a rede de vigilância que afirma o que deveria ser o bom professor e as boas qualidades da docência? Rejeitando a ideia de que os professores são aplicadores de conteúdo, instrumentos de uma educação maior, em sintonia com o projeto certeauniano de reconduzir as práticas e as línguas científicas ao seu país de origem, a everyday life, explorando combinações táticas que se infiltram nas brechas do poder, o presente texto - fruto de uma pesquisa de doutoramento em curso intitulada "Artes de ensinar geografias: inventividades, trajetórias de vida e saberes docentes" -, se propõe a pensar as riquezas escorregadias do cotidiano que evidenciam a fertilidade efêmera da criatividade docente, em torno de dois eixos: os professores como praticantes ordinários e suas aulas como inventividades docentes. $\mathrm{Na}$ contramão da desprofissionalização implícita nos baixos salários, das condições precárias de trabalho, das lógicas de burocratização e controle e da visão técnica e prática do ofício do professor, almeja afirmar o processo profissional artesanal e astucioso que caracteriza a docência.

Palavras-chave: Ensino de geografia(s). Michel de Certeau. Práticas ordinárias. Inventividades docentes

\section{AT SCHOOL, NOT ALL CATS ARE BROWN: ARMING A PERSPECTIVE TO SEE THE ARTS OF TEACHING GEOGRAPHIES}

\begin{abstract}
How do teachers play in the field of curriculum parameters and bases? How do they deal with job insecurity and the lack of adequate conditions to work? How to face these questions, but without romanticizing oppression? On the other hand, how to consider the surveillance network that affirms what should be a good teacher and the good qualities of teaching? Rejecting the idea that teachers are content applicators, instruments of a higher education, in line with the certeaunian project to bring scientific practices and languages back to their country of origin, everyday life, exploring tactical combinations that infiltrate the gaps of power, this text - the result of an ongoing doctoral research entitled "Arts of teaching geographies: inventivities, life trajectories and teaching knowledge" -, proposes to think about the slippery riches of everyday life that show the ephemeral fertility of teaching creativity,
\end{abstract}


around two axes: teachers as ordinary practitioners and their classes as inventiveness teachings. Against the deprofessionalization implicit in low wages, precarious working conditions, the logic of bureaucratization and control and the technical and practical vision of the teacher's profession, it aims to affirm the artisanal and crafty professional process that characterizes teaching.

Keywords: Teaching of geography(s). Michel de Certeau. Ordinary practices. Teaching inventivities

\section{EN LA ESCUELA, NO TODOS LOS GATOS SON MARRONES: ARMANDO UNA PERSPECTIVA PARA VER LAS ARTES DE ENSEÑAR GEOGRAFÍAS}

RESUMEN: ¿Cómo juegan los profesores en el campo de los parámetros y bases curriculares? ¿Cómo tratan con la precariedad laboral? ¿Cómo hacer frente a esas cuestiones, pero sin romantizar la opresión? Por otro lado, ¿cómo considerar la red de vigilancia que afirma lo que debe ser un buen docente y las buenas cualidades de la docencia? Rechazando la idea de que los docentes son aplicadores de contenidos, instrumentos de una educación más grande, en línea con el proyecto certeauniano de devolver las prácticas y los lenguajes científicos a su país de origen, la everyday life, explorando combinaciones tácticas que se infiltran en las brechas del poder, este texto - resultado de una investigación doctoral en curso titulada "Artes de la enseñanza de las geografías: inventividades, trayectorias de vida y conocimiento de la enseñanza" -, propone reflexionar sobre las escurridizas riquezas de la vida cotidiana que muestran la efímera fecundidad de la creatividad docente, en torno a dos ejes: los profesores como practicantes ordinarios y sus clases como inventividades docentes. Frente a la desprofesionalización implícita en los bajos salarios, las precarias condiciones laborales, la lógica de burocratización y control y la visión técnica y práctica de la profesión docente, se pretende afirmar el proceso profesional artesanal y astucioso que caracteriza la docencia.

Palabras clave: Enseñanza de geografía(s). Michel de Certeau. Prácticas ordinarias. Inventividades docentes

\section{INTRODUÇÃO}

Em paralelo com a vida universitária, as leituras e os debates sobre o ensino de geografia, está a vida comum, em grande parte dividida com minha querida mãe, Dayse, em uma pequena chácara. Como principal incentivadora, muitas vezes me advertiu: a geografia também está no quintal, precisa ter atenção aos detalhes. Como perceber as injustiças do mundo se não nota que plantei uma nova flor? Com mais ou menos essas palavras, ou até outras, foram precisos anos, novos encontros e literaturas para entender o que ela me ensinava e persiste em ensinar. Por conta disso, há algum tempo venho tentando exercitar a perspicácia de "ver" plantas antes invisíveis através dos seus complexos saberes e invenções de paisagismo. Tais sutilezas se expressam em muitas dimensões, como no desejo de sempre reconfigurar os caminhos feitos de pesadas pedras e, com isso, os modos criativos de continuar independente, embora a força física esteja em transformação. Parte do muro caiu, faz uma cerca viva. Observa cada tom de verde, e explora os usos da grama-amendoim para abafar aqueles matos altos indesejados. Planta árvores volumosas próximo às janelas para preservar a privacidade. Observa quais flores se dão bem no sol e quais preferem a sombra, além de aproveitar o aroma das damas da noite que envolvem o ar. Chegando ao fim destas linhas, devem estar se perguntando: entre jardinagem e artes de ensinar geografias, qual sentido se camufla? Se assim acontecer, posso contar de novo, seguir enumerando outras táticas silenciosas e inspiradoras das artes de plantar. Não desejo mais perder o horizonte das belezas comuns (Do memorial da autora). 
$* * *$

Uma vez no Kingston estávamos falando sobre ditados populares e em algum momento algum aluno falou sobre "tudo acabar em pizza". Foi o que precisava para montarmos um rodízio. Eles levaram os recheios da preferência deles e eu levei as massas prontas de mercado. O preparo foi maravilhoso! Um interação bem legal! (Relato da professora Hellen Ferreira)

Pegando carona nos ditados populares, lembro também desse outro: "à noite todos os gatos são pardos". Com a denúncia de que a visão não é onipotente, que se influencia fatalmente pela claridade, fica a consequência: uma visibilidade que oscila entre o monocromático e o multicolorido. Desse mesmo modo acontece com as luminosidades teóricas, que fazem vislumbrar diferentes tonalidades, umas mais homogêneas, que perpetuam lentes rústicas o bastante para apagar o admirável criado nas escolas, outras mais plurais. O presente texto, fruto da pesquisa de doutoramento em curso, intitulada "Artes de ensinar geografias: inventividades, trajetórias de vida e saberes docentes", se propõe justamente a armar uma perspectiva para "ver" detalhes invisíveis na imensidão daquilo que é conhecido como "mais do mesmo" na profissão. Quais cores se apresentam quando, por um lado, não se reduz a docência à análise cirúrgica das insuficiências ou, por outro, não se trata de uma caçada ao professor ideal? A inspiração trazida do título para cá perguntar para ver, não necessariamente encontrar respostas, posto que as questões sociais não trazem soluções prontas em seus enunciados -, veio de Beatriz Sarlo: "não são perguntas sobre o que fazer, mas sobre como armar uma perspectiva para ver" (SARLO, 2013, p. 18).

Através das artes de ensinar geografias - expressão cunhada no plural com a intenção de refletir na linguagem as muitas experiências docentes que anonimamente disputam o cotidiano das escolas - nos moveremos com a finalidade de chegar àquelas situações das salas de aula que operam ações de uma educação menor, realizada pelo "pequeno 'faz-tudo' do dia a dia, cavando seus buracos, minando espaços, oferecendo resistência" (GALLO, 2017, p. 68). Nossa análise se concentrará no cotidiano, sendo assim, que orientações teórico-metodológicas nos guiaram para decifrá-lo? Procuramos estabelecer uma inter-relação entre os estudos de Michel de Certeau (1998; 2013) e a compreensão de que os professores não são as técnicas didáticas que eles mobilizam ou criam, mas o conjunto do que eles constroem entre as suas trajetórias e os seus fazeres e saberes. Desse modo, ensaiamos reflexões construídas a partir da empiria da observação de aulas de professores de geografia que foram realizadas em duas instituições de ensino: uma pública de nível fundamental e um curso pré-vestibular privado. Incorporamos também, em uma perspectiva (auto)biográfica, conversas e narrativas profissionais, além de elementos do memorial de um(a) 
dos(as) autores(as) para pensar a seguinte provocação: "O que a vida de todos os dias pode mostrar de 'útil' à pesquisa científica, particularmente na área da educação?” (OLIVEIRA, 2001, p. 39).

Entre conversas profissionais com Hellen, amiga e professora de português, daquelas inspiradoras, reformulamos de modo mais informal a inquietação de Oliveira (2001): das suas práticas docentes do dia a dia, o que elegeria para contar? Não de forma inocente nem descompromissada, desejávamos rememorar os seus pequenos prazeres docentes, aqueles que já conhecíamos e muito tínhamos ouvido falar quando compartilhávamos o mesmo Kingston, para fazer deles centelha de pensamento. Em contrapartida, ela diz: "Tem muitos momentos, mas, ao mesmo tempo, nenhum". A complexidade da afirmação não nos pegou de surpresa; afinal, que professor não foi impelido a fugir do lugar comum? Leia-se: colocar em ação práticas pedagógicas diferentes das corriqueiras, além do que prescreve o currículo oficial. Sendo assim, o que narrar? Talvez esta leitura massificada da reprodução, sempre vigilante e colocando constantemente em xeque os fazeres e saberes docentes, seja parte da explicação do nenhum, de uma coisa qualquer a falar, que em certo sentido leva à compreensão da educação básica mais para perto de uma dualidade, na base do tudo ou nada, do que da sua inesgotável ambivalência.

Entre conteúdos curriculares prescritos e culinária, uma constatação: "No fim a gente acaba achando tudo tão comum que não vê o quão legal e criativo aquilo foi”. Incorporamos as palavras da Hellen aos nossos anseios de pesquisa, provavelmente ditas por razões muito distantes das hipóteses teóricas que nos instigam, para caminhar junto delas como se partissem em direção a uma bifurcação: de um lado, reafirmam o desafio de pensar as riquezas escorregadias (OLIVEIRA, 2001) do cotidiano; do outro, evidenciam pistas da fertilidade efêmera da criatividade docente. Este cruzamento nos leva ao objetivo deste artigo, isto é, atentar para duas frentes complementares que possibilitam outros modos de entendimento das artes de ensinar geografias: os professores como praticantes ordinários e suas aulas como inventividades docentes.

\section{PERIGO E POTÊNCIA: PROFESSORES COMO PRATICANTES ORDINÁRIOS?}

Das pressuposições mais imediatas, daquelas que se fazem apenas com uma passada de olhos, o risco se encontra logo evidente quando se lê a palavra professor seguida na mesma frase do adjetivo ordinário. Em um jogo de semântica arriscado, diante de um contexto de desconfiança acirrado, todo cuidado é pouco. De pronto, poderia causar a impressão de ser uma perspectiva que rebaixa a condição da docência e o prestígio simbólico dos professores; ou, quando não mais 
contemporizadora, se aproximar de uma crítica veemente: o professor como alguém que está longe do brilhantismo, do notável.

Ordinário, antônimo de extraordinário, se volta para a dimensão do comum e aí, talvez, esteja o incômodo. O banal não é sempre o que não se deseja nem se prescreve? E esta é justamente a aposta: se distanciar do único ou do atípico e concentrar os esforços nos aspectos corriqueiros das práticas docentes, em geral desconsiderados ou desvalorizados. Antes disso, porém, sublinhe-se o fato de que não desconhecemos as interpretações de professor-pesquisador ou de professorreflexivo, que não nos contrapomos a elas, exatamente, mas dirigimos o olhar para outros aspectos relevantes da docência, aqueles hipoteticamente já conhecidos da multidão sem rosto.

Sendo assim, caminhamos ao lado de Michel de Certeau - e por largas passadas neste texto! - como referência importante para esse diálogo por ter se dedicado a pensar o herói comum, o ordinário. A erosão do coro que invocava os donos de nomes próprios ainda faz emergir uma inquietação que se renova através de outras denominações, mas que sempre quer saber: "o que é que pedimos para nos fazer crer ou autorizar-nos a dizer quando lhe dedicamos a escrita que outrora se oferecia em homenagem aos deuses ou às musas inspiradoras?” (CERTEAU, 1998, p. 57). Sem se render ao discurso da modernidade, que reduz os caminhantes inumeráveis a heróis quantificados, Certeau se volta para o ordinário como o indizível, e não objeto universal abstrato, o que consiste em "reconduzir as práticas e as línguas científicas para seu país de origem, a everyday life, a vida cotidiana" (id, ibid, p. 64).

O sentido do ordinário se reconfigura quando é devolvido às redes de poder do dia a dia, entretanto não para enfatizar o "mundo enfeitiçado pelos poderes invisíveis do Outro" (id, ibid, p. 99), mas para se esquivar da problemática privilegiada que diz haver uma fatalidade intransponível estabelecida pela repressão daqueles que comandam as estratégias, isto é, pelo

cálculo das relações de força que se torna possível a partir do momento em que um sujeito de querer e de poder é isolável de um "ambiente". Ela postula um lugar capaz de ser circunscrito como um próprio e portanto capaz de servir de base a uma gestão de suas relações com uma exterioridade distinta (CERTEAU, 1998, p. 46).

Quando não se é o próprio, ou não se tem a visão globalizante, o que sobra? Resta o tempo, o senso da ocasião e a destreza das trampolinagens, "astúcia e esperteza no modo de utilizar ou de driblar os termos dos contratos sociais” (CERTEAU, 1998, p. 79). Esses pequenos atos de criação, que operam "golpe por golpe, lance por lance" (CERTEAU, 1998, p. 100), e que se baseiam na 
ideia de que as práticas cotidianas são dotadas, simultaneamente, de assimilação e resistência, Certeau chama de tática, ou seja, a

ação calculada que é determinada pela ausência de um próprio. Então nenhuma delimitação de fora lhe fornece a condição de autonomia. A tática não tem por lugar senão o do outro. E por isso deve jogar com o terreno que lhe é imposto tal como o organiza a lei de uma força estranha (CERTEAU, 1998, p. 100).

As situações impostas ou as estratégias, como aquelas já há muito tempo conhecidas, desde o currículo prescrito e as avaliações externas até os autoritarismos de algumas direções escolares, deixam evidente que as artes de ensinar geografias, ou matemáticas, ou histórias, se inscrevem em um sistema que não dominam, porém são o seu contraponto no mesmo lugar. É essa arte do jogo sutil de saltar no terreno do outro que nos faz caracterizar o professor como ordinário, que tem na tática a arte do fraco. Abre brechas para interpretar, como dizem Selles e Andrade (2016), o "jogo jogado", as mediações construídas no encontro entre professores e estudantes, contra uma "visibilidade 'panóptica' de uma escola abstrata, vista do 'alto"” (OLIVEIRA, 2001, p. 50), ou totalmente submersa na compreensão de uma imobilidade tutelada.

Ao rejeitarmos a ideia de que os professores são meros aplicadores de conteúdos, ou instrumentos de uma educação maior (GALLO, 2017), nos posicionamos a partir de uma leitura cega em amplitude, contudo perspicaz do corpo a corpo, maneira de fazer própria do ordinário, que pela ausência do poder, joga com ele.

Embora sejam relativas às possibilidades oferecidas pelas circunstâncias, essas táticas desviacionistas não obedecem à lei do lugar. Não se definem por este. Sob este ponto de vista, são tão localizáveis como as estratégias tecnocráticas (e escriturísticas) que visam criar lugares segundo modelos abstratos. O que distingue estas daquelas são os tipos de operações nesses espaços que as estratégias são capazes de produzir, mapear e impor, ao passo que as táticas só podem utilizá-los, manipular e alterar (CERTEAU, 1998, p. 92).

Como jogam os professores no terreno dos parâmetros, diretrizes e bases comuns curriculares? Como lidam com a precarização do trabalho que superlota salas de aula? Ou com a ausência de materiais para trabalhar? Assim como Certeau, não desejamos romantizar as opressões, tampouco engrossar o refrão que diz que "acima de tudo, é possível quando se trabalha por amor", mas construir uma análise desse inventário de combinações táticas, que se infiltram onde ninguém espera, de acordo com as brechas deixadas pelas conjunturas de poder. Não destituem as políticas 
prescritas, atuam nas falhas e fazem das salas de aulas trincheiras (GALLO, 2017) que mobilizam transformações sociais, por menores que sejam.

Identificar o funcionamento do poder instituído é essencial, como assinala Certeau (1998) sobre a produção de Foucault em Vigiar e Punir, entretanto, dialogando com ele, faz uma alegação crucial:

Se é verdade que por toda a parte se estende e se precisa a rede de "vigilância", mais urgente ainda é descobrir como é que uma sociedade inteira não se reduz a ela: que procedimentos populares (também minúsculos e cotidianos) jogam com os mecanismo da disciplina e não se conformam com ela a não ser para alterá-los; enfim, que "maneiras de fazer" formam a contrapartida, do lado dos consumidores (ou dominados?), dos processos mudos que organizam a ordenação sócio-política (id, ibid, p. 41).

Uma rede de vigilância atenta diz com precisão aquilo que deveria ser o bom professor, as boas qualidades da docência, mas o que efetivamente a profissão docente e o professor fazem de si continua por se explorar. Desse modo, reconhecer que o controle sobre o cotidiano escolar não é soberano possibilita o anúncio da inteligência contida nos golpes mudos dos professores. Produtores desconhecidos, como interpretar, em profundidade, tais minúcias que caracterizam os mecanismos efêmeros das criações escolares?

Aula de geografia e direitos humanos na 811. Escrevo no quadro: DIREITOS X DEVERES. Começo a problematização pelo universo escolar para chegar à ideia de que numa sociedade desigual alguns possuem mais direitos, ou melhor, possuem privilégios em função de raça, classe, sexualidade e gênero. Em meio ao falatório, uma mão inquieta insiste em pedir a palavra na tentativa de cumprir o acordo, já esquecido por muitos, de aguardar a sua vez. Maria Clara me questiona, mas sem a intenção de perguntar, pelo contrário, afirma com o detalhe de ter como entonação o ponto de interrogação: - Professora, por que quando falam homens e mulheres, as mulheres vêm sempre depois dos homens? Isso é desigualdade, né? Reconstruo as minhas frases e sigo, então, falando sobre pretas e pretos, trabalhadoras e trabalhadores, mulheres e homens, agora com atenção redobrada. Ao fim, já cansada, me volto pro quadro e escrevo um pequeno resumo da aula (Relato da autora na EM Clério Boechat de Oliveira, em 2020).

Em meio à ebulição, como reflexo de todo debate feito em uma sala com quarenta alunas e alunos - lembrando que a ordem dos gêneros é consequência das desigualdades, como diria Maria o que estamos preparados para “ver”? Quem sabe uma reflexão tradicional com algumas pitadas de criticidade, porém que ainda assim reforça a disciplinarização dos corpos escolares, do "bom 
estudante", aquele que sabe suas obrigações. A partir de qual perspectiva se voltariam as atenções para a velha ação docente de aproveitar o quadro quando já não se tem forças e voz para falar?

Pensar as táticas é pensar sobre as ocasiões e as manipulações que delas se originam, levando em consideração as redes institucionais e as suas tramas.

Quanto maior um poder, tanto menos pode permitir-se mobilizar uma parte de seus meios para produzir efeitos de astúcias. (...) Ao contrário, a astúcia é possível ao fraco, e muitas vezes apenas ela, como "último recurso": "Quanto mais fracas as forças submetidas à direção estratégica, tanto mais esta estará sujeita à astúcia". Traduzindo: tanto mais se torna tática (CERTEAU, 1998, p. 101).

A arte dos desvios se encontra nas situações comuns, que de tão infinitesimais se camuflam de ordem enquanto fabricam formas de metamorfosear a lei, seja ela ideológica, que diz serem todos iguais, ou disciplinar, pedagógica, geográfica... É preciso estar atento às ocasiões, às vezes bem propícias, como quando o tema gerador dos projetos da secretaria de educação é "É de Maricá, é de todos!". Ou ainda, quando a aula acontece na única sala do primeiro andar da escola, longe dos inspetores, e as vozes podem correr soltas, "protegidas" dos comentários que dizem: “Essa professora não tem controle de turma!". Por outra mirada, poderíamos apontar para táticas como a da Maria, assim como de outros estudantes, que afirmam perguntando para não cometerem o "erro" de dizer algo que vá de encontro ao que pensa a professora, que detêm o saber legitimado. Seria sempre o professor ordinário?

Há uma dinâmica intricada que povoa os cotidianos escolares e que nos coloca no lugar do fraco e do forte na mesma aula, em instantes diferentes da mesma explicação. Voltaremos nossos esforços, todavia, para a captura das táticas que escapam às leituras do campo acerca das geografias, sem desconsiderar que os professores também assumem o lugar e o tempo em diferentes circunstâncias. Como diria Certeau, seriam estrategistas na medida em que nas relações de forças com os estudantes ostentem o papel daquele que impõe as regras do jogo. Que posicionamentos fazem de nós, professores, estes sujeitos de querer e de poder? Nesse sentido, estratégias e táticas coabitam as pessoas comuns, e se mesclam de tal modo que impedem uma interpretação linear da vida, inclusive da vida escolar.

Ao rememorar a experiência anteriormente narrada, que outras mais os professores poderiam contar, nos aproximamos da provocação de Certeau (2013) acerca do desconhecimento das práticas ordinárias que, por vezes reduzidas a um padrão, nos impede de perceber o que há de 
antidisciplinar, desordeiro e criador, apesar de pertencerem a uma ordem, disciplina, ou até certa obediência.

Para além de uma dita superficialidade da repetição e de uma análise simplificadora, em direção à produção de singularidades, a opção por entender os professores como praticantes ordinários não tem a intenção de os retirar do campo profissional que ocupam e que buscam consolidar, ao contrário, almeja afirmar a profissão docente. Na contramão da desprofissionalização que, como aponta Nóvoa (2017), se evidencia entre outras maneiras, através dos baixos salários, das condições precárias de trabalho nas escolas, das lógicas de burocratização e controle e da visão técnica e prática do trabalho, inerente ao que a literatura crítica tem denominado de paradigma da racionalidade técnica, está a proposta de apreensão do processo profissional artesanal e astucioso que caracteriza a docência.

Ao nos guiarmos pelo pressuposto de que as práticas dos professores são do tipo tático (CERTEAU, 1998), e por isso artes de ensinar, assumimos como imperativa a necessidade de considerar que há uma provisoriedade intrínseca nesta concepção, que impulsiona a construção de um olhar específico para o entendimento das suas criações curriculares. Com a intenção de nos permitir "imaginar a incrível abundância inventiva das práticas cotidianas” (CERTEAU, 2013, p. 342), voltaremos as atenções para as inventividades docentes.

\section{PORMENORES: LAPIDANDO O CONCEITO DE INVENTIVIDADES DOCENTES}

"O cotidiano se inventa com mil maneiras de caça não autorizada."

(CERTEAU,1998, p. 38)

A posição de não autorizado evidencia a distribuição desigual de forças entre os sujeitos, porém não impossibilita a caça ou as "astúcias multimilenares dos peixes disfarçados ou dos insetos camuflados" (id, ibid, p. 38). Existem mil maneiras de fazer, ocultadas pela racionalidade dominante, que nos fazem interrogar: de que astúcias lançam mão os mais fracos? Para adentrar os meandros desta questão, que envolve mais o interesse pela artesania de quem recria do que o poder de quem impõe, um deslocamento é fundamental: sair do lugar que pressupõe a reprodução passiva para explicitar os modos de operações anônimas que "saem da linha e derivam num relevo imposto, ondulações espumantes de um mar que se insinua entre os rochedos e dédalos de uma ordem estabelecida" (id, ibid, p. 97). 
Sendo assim, que mil maneiras de ensinar geografias não autorizadas se realizam nas aulas? Para investigar estas geografias minúsculas, fruto da "atividade de formigas" (CERTEAU,1998), a noção de uso/consumo empregada por Certeau se coloca como possibilidade generosa para interpretar a pluralidade das artes de ensinar dos professores na construção de suas microresistências. Sobre esta arte de "fazer com" Certeau (1998) assinala:

$\mathrm{Na}$ realidade, diante de uma produção racionalizada, expansionista, centralizada, espetacular e barulhenta, posta-se uma produção de tipo totalmente diverso, qualificada como "consumo", que tem como característica suas astúcias, seu esfarelamento em conformidade com as ocasiões, suas "piratarias", sua clandestinidade, seu murmúrio incansável, em suma, uma quase-invisibilidade, pois ela quase não se faz notar por produtos próprios (onde teria o seu lugar?) mas por uma arte de utilizar aqueles que lhe são impostos (id, ibid, p. 94).

Seguindo na direção desta produção de outro tipo, a dos pormenores, exploraremos os modos de consumir a Geografia maior, aquela da ciência geográfica e dos currículos oficiais e, com isso, os procedimentos de fabricação das geografias menores (OLIVEIRA JR., 2019), que podem causar um grande distanciamento entre elas, ou conservar diferenças quase-invisíveis, mas que certamente não são correspondentes. A esta arte de reciclagem a partir de dentro, não rejeitando ou necessariamente transformando porém, astuciosamente fazendo uso da produção dominante, chamaremos de inventividades docentes. Elas redesenham as intersecções entre o conhecimento científico e os outros saberes sociais que se encontram na clandestinidade, tendo duas dimensões intrínsecas que as caracterizam: a criatividade e o desvio.

\section{A CRIATIVIDADE E O DESVIO}

Amplamente reconhecido o valor do estímulo à criatividade na educação básica, somado ao desejo por uma "escola do século XXI", porém, temos a validação das críticas que ecoam a falência do ensino tradicional, aliada aos pedidos urgentes por mudanças nas práticas pedagógicas. As atenções se voltam para o importante papel do professor: propostas de ensino/aprendizagem criativas oportunizam jovens criativos. Em um levantamento de pesquisas brasileiras sobre a criatividade docente, entretanto, Nakano (2009, p. 45) aponta que os professores estão mal preparados para lidar com a pluralidade de estudantes, desconhecem estratégias criativas e estimuladoras para ensinar, além de estarem desmotivados frente às condições de trabalho e ao amplo programa curricular que precisam cumprir. 
Levando em consideração este cenário, e o que já foi dito sobre as "sérias dificuldades enfrentadas na sala de aula" (ZANATTA, 2010), as geografias ainda assim podem ser criativas? O que se ventila são apostas no potencial, no vir a ser, já que existe certo consenso discursivo de que a criatividade se encontra abafada nas escolas, o que gera uma constatação generalizante que se repete: as aulas não são suficientemente atrativas para os estudantes, e desse modo, o ensino de geografia pode, porém não exatamente é.

Uma pergunta que não se cala: "Como estimular a criatividade na prática docente da Geografia Escolar contemporânea?” (COPATTI, 2017). No campo da educação, a criatividade está, por vezes, vinculada à concepção de inovação pedagógica ou educacional, comumente direcionada para a "solução dos problemas que assolam a educação", ou também ao emprego de novas tecnologias, ainda que não apresente uma clareza em seu significado, já que os sentidos do conceito diferem entre si de acordo com a pluralidade de entendimentos e de concepções epistemológicas (TAVARES, 2018). Outra questão, todavia, se faz necessária: quais expectativas - ou prescrições? - determinam o que é criativo ou não? Alguns mitos que acompanham a concepção de criatividade nos ajudam a refletir.

Dentre os inúmeros mitos associados à criatividade, destaca-se a sua concepção como um dom presente em apenas alguns poucos indivíduos. Também frequente é a visão errônea da criatividade como uma questão de tudo ou nada, considerandose alguns indivíduos como criativos e a grande maioria como não-criativa. Ainda comum é a ideia de que a expressão criativa ocorreria independentemente das questões ambientais, predominando uma concepção unilateral da criatividade, como um fenômeno eminentemente individual e intrapsíquico. É necessário salientar, entretanto, como ponto de partida, que a criatividade é algo inerente a natureza humana: todo ser humano é criativo, podendo a criatividade se apresentar através de distintas formas e em diversos graus (ALENCAR, 2002, p. 166).

Seguindo a premissa de Alencar (2002) de que todo ser humano é criativo, poderíamos concluir que todos os professores são criativos? Ao tornar a criatividade um pressuposto, abandonamos a espera por determinadas atitudes pedagógicas e voltamos a atenção para a análise dos usos das inúmeras situações pedagógicas corriqueiras vivenciadas nas aulas. Ao deixar de pertencer exatamente a um imaginário formulado à priori, voltado para o (extra)ordinário, práticas marcadas pela exceção, aquele "professor diferente", aquela famosa "aula diferente", a criatividade aqui se configura pelas "mil maneiras de fazer" e os seus contextos.

Percorremos o caminho que entende a criatividade não como uma finalidade ou uma metodologia desejável ao processo educativo, mas como um senso da ocasião, a arte de "dar um 
golpe" silencioso na direção da insurgência da produção de conhecimentos entre estudantes e professores. As inventividades, desse modo, não se relacionam necessariamente à novidade, ao não visto ou vivido, mas a utilização das circunstâncias para a problematização de uma situação pontual. Feita de descontinuidades, no entanto compromissada com pequenos ganhos diários, a criatividade ordinária está contida nas burlas, isoladas ou coletivas, que se apresentam fragmentadas numa orquestra de murmúrios incansáveis. Diante de um cenário que não joga ao seu favor, é a busca por saídas que desembocam em uma criação desviante, através de caminhos por vezes quase lineares, outros bem sinuosos.

\section{A CULTURA ORDINÁRIA}

A pesquisa das inventividades como possibilidade de interpretação da docência, especialmente dos professores de geografias, não significa propor um novo paradigma, aliás, não tem intenção de ser mais um rótulo que separa as ditas boas das más práticas. Todos os professores são inventivos, porém de distintas formas. Como analisar tais inventividades? Distante da proposição de um modelo replicável de análise, Certeau nos aponta pistas para a interpretação das articulações criativas e desviantes do cotidiano, em meio às suas complexidades aparentemente simples. E adverte:

O essencial do trabalho de análise que deveria ser feito deverá inscrever-se na análise combinatória sutil, de tipos de operações e de registros, que coloca em cena e em ação um fazer-com, aqui e agora, que é um ato singular ligado a uma situação, circunstâncias e atores particulares (CERTEAU, 2013, p. 341).

As pesquisas nos/dos/com/os cotidianos, em grande parte também inspiradas por Certeau, estimuladas pela captura das operações escolares e sua originalidade, contribuem ao chamar atenção para o descompasso existente entre o objetivo de perceber situações reais da vida escolar e os procedimentos clássicos de pesquisa. Apontam que outras lógicas, que não aquelas que se estruturam em modelos explicativos das ações pedagógicas, devem ser construídas para que não se insista na realização de leituras gerais, que pouco favorecem o enredamento de saberes e práticas constituintes dos hábitos banais.

A trivialidade do cotidiano encobre aquilo que durante muito tempo foi tido como ilegítimo e/ou negligenciável para a ciência - que de certo modo perdura -, isto é, a cultura oral, os praticantes e a vida comum. Para Certeau (2013), analisar a cultura ordinária por meio dos seus usos, nos códigos particulares dos praticantes, significa reconhecer os alicerces que a sustentam e 
organizam: a oralidade, a operatividade e o ordinário. À vista disso, seus escritos são provocadores quando pensados a partir da escola, que é marcada, de algum modo, por esse tripé. Tendo o professor como o ordinário, argumentaremos em torno da oralidade e da operatividade como possíveis chaves interpretativas das inventividades docentes.

\section{ARTES DE DIZER: POR UMA ARQUEOLOGIA DAS VOZES ESCOLARES}

... muitas línguas africanas conservaram uma fraseologia mostrando que as culturas correspondentes não elaboraram o conceito geral de palavra: uma multiplicidade de atos vocais assume funções sociais distintas umas das outras.

(Paul Zumthor. Performance, recepção, leitura, p. 39.)

Se para Paul Zumthor (2014) a oralidade transcende a própria noção de palavra, em Michel de Certeau (2013) temos o reconhecimento do seu papel fundante na relação com o outro, e como constituinte das configurações que se estabelecem no cotidiano. Ainda que a escrita tenha se tornado um veículo organizador do mundo, a oralidade está situada em duas dimensões que se enlaçam: a do aprender e a da comunidade. Do ponto de vista da circulação do saber, seus rituais de mensagens entre sons e sentidos, de imediato chegamos até a escola. Um relato sobre a docência em tempos de pandemia talvez reforce esta constatação.

Duas prefeituras, duas estratégias em tempos de ensino remoto. Uma delas optou pela produção de apostilas, que foram entregues a todos os estudantes da rede. A outra investiu em uma plataforma educacional digital. Propostas diferentes, que geraram nos estudantes, e nas suas famílias, dúvidas iguais: vai ter aula online ao vivo? Esta foi a pergunta que não quis calar, tanto em Saquarema, quanto em Maricá (Relato de experiência profissional da autora).

A educação básica, descolada das vozes escolares, organizadoras e reorganizadoras desse lugar através das "músicas de sons e de sentidos, polifonias de locutores que se buscam, se ouvem, se interrompem, se entrecruzam e se respondem" (CERTEAU, 2013, p.336), se tornou temporariamente nostalgia. Neste contexto educacional atípico emergiu com força dimensões que não eram colocadas em questão como indispensáveis: a voz e o corpo do professor. Eles, em muitas realidades, agora são a escola. Relegados a um segundo plano, percebidos apenas como meios de transmissão do currículo, uma estrutura física que fala a matéria, o enfoque longevo tem sido, em geral, mais uma leitura racional do que propriamente sobre a sua capacidade de produzir experiências de conhecimento. Mudaram os sentidos quando, agora, os professores se tornam a própria escola? 


\section{SOBRE VOZES E GEOGRAFIAS}

Táticas de explicação do conteúdo escolar, sem dúvida, representam o que primeiro vem à mente quando se propõe investigar as artes de dizer, atualmente em alta, já que muitos depoimentos de responsáveis repetem: "eu sei a matéria, mas não sei explicar". Repito: só o conhecimento geográfico basta? A paisagem de uma memória juvenil em Paris e os cantores de rua, recriada por Zumthor (2014), nos fazem entender que a canção das suas lembranças não se reduzia apenas à letra ou ao dizer a letra: eram os risos das meninas, os barulhos do mundo, o céu no começo de inverno...

Decompor uma aula por meio do que é dito constitui uma perspectiva indispensável da docência em função de demarcar o conhecimento profissional (MATTOS, 2006). Todavia, se isolado do universo complexo que é a sala de aula, reduziremos o saber docente aos seus aspectos verbais e cognitivos - imprescindíveis -, negando o não-dito, o vivido. Reestabelecer o texto ao seu contexto ou, como na cultura escolar, reintegrar a matéria explicada às circunstâncias, ao ambiente e suas vozes vivas é o que estamos chamando de arqueologia. Esta reconstrução, tendo a oralidade como elemento central, sendo ela corriqueira em todos os espaços, nos faz questionar, junto com Certeau: "como creditar inteligência e complexidade requintada às astúcias de uma prática tão comum?" (2013, p. 338). Trazida para o universo escolar, e preenchida por antigas interpretações, feitas em tom de crítica, reformulamos do seguinte modo: como creditar inteligência e complexidade requintada às artes de dizer que são, por vezes, tratadas como mero "cuspe e giz"?

O que nos movimenta, nesse sentido, são as possibilidades de reinterpretar o "cuspe e giz" por outro viés, que não o da repetição e da monotonia. Nos inquieta o que não se sabe sobre o "cuspe e giz", ou, além disso, o questionamento: qual é a "poética escondida" nessa prática tão comum? Por poética interpretamos, com Paul Zumthor, "uma arte da linguagem humana, independente de seus modos de concretização e fundamentada nas estruturas antropológicas mais profundas" (ZUMTHOR, 2014, p. 16). Seria a busca por compreender o processo de ensinoaprendizagem levando em conta as sensibilidades, a presença corporal do professor, seus efeitos na construção do conhecimento via oralidade? Isto é, com efeito “a voz, não somente nela mesma, mas (ainda mais) em sua qualidade de emanação do corpo e que, sonoramente, o representa de forma plena" (ZUMTHOR, 2014, p. 27).

De outra natureza, porém não oposta, as artes de ensinar não se revelam propriamente através da economia escriturística (CERTEAU, 1998), que rege as pesquisas acadêmicas, assim como esta, o que aprofunda o isolamento entre a voz dos professores e os ruídos que sobre ela se 
formulam. Ao não se materializar na escrita, mas na aula falada, nas explicações, nos gestos, no caminhar, quando o sinal toca, marcando o final do encontro, inevitavelmente se perde o registro daquela engenhosidade minúscula, que só será medida e valorizada, ou não, nos termos da cultura escolar, por meio das atividades, testes e trabalhos que, via de regra, apagam sua origem na oralidade.

Perceber esta condição que é efêmera por si mesma, momento singular de interação, enquanto uma complexidade requintada que está próxima da invisibilidade ao fim de cada aula, faz parte da construção de uma paisagem sonora (CERTEAU, 1998) da docência. Um cenário cotidiano de anônimos "jogos da linguagem”, constituído através de conflitos e interesses que ultrapassam as palavras, que se insinuam por meio da identidade dos interlocutores, das circunstâncias, dos contextos e da "materialidade dos sons". É o que nos diz Certeau sobre as "artimanhas, desvios semânticos, quiproquós, efeitos sonoros, palavras inventadas, palavras deformadas" (2013, p. 338). Além do enunciado, atenção também àquilo "que não diz respeito à palavra nem a frase" (CERTEAU, 2013, p. 338).

Que professor, embora não compactue, nunca ouviu dos estudantes tais frases: "Ela(e) explica bem, mas a voz dela(e) é irritante". "Ela(e) só fala gritando". "A gente não fica quieto, aí o(a) professor(a) comprou um microfone!". Quem nunca negociou no sexto ano: "Vou falar baixinho, quem quiser que fique quieto para escutar", não sabe o que é uma disputa de sons entre "eu quero aprender", dizem uns, outros aumentam o som dos fones de ouvido, alguns continuam suas conversas paralelas, uns fazem silêncio e observam, e a aula continua, evidentemente, sem cumprir a tal diminuição do tom prometida, com um certo sinal de ameaça. É inegável que o sensível das entonações, pronúncias, pausas e timbres, aliados ao inteligível, ao que se diz e como se diz, conservam um papel primordial no entendimento das artes de ensinar.

\section{OPERAÇÕES DO ENSINAR GEOGRAFIAS}

A arte de dizer, distinguível pela singularidade, não está apartada da corporeidade. Percepção sonora, e, ao mesmo tempo, visual, tátil, olfativa, são indissociáveis. O que o corpo ensina e aprende, mesmo sem nos darmos conta? Ainda que sejam aproximações a serem exploradas no processo de pesquisar, de outro modo, ao ver, ouvir e sentir, enfatiza-se que estas nuances devem envolver o tratamento das operações docentes que, segundo Certeau (2013), possuem três aspectos: estético, polêmico e ético. 
Um primeiro aspecto dessas operações é o estético: uma prática cotidiana que abre um espaço próprio numa ordem imposta, exatamente como faz o gesto poético que dobre ao seu desejo o uso da língua comum num reemprego transformante. Um segundo aspecto é polêmico: a prática cotidiana é relativa às relações de força que estruturam o campo social e o campo do saber. Apropriar-se das informações, colocá-las em série, montá-las de acordo com o gosto de cada um é apoderar-se de um saber e com isso mudar de direção a força de imposição do totalmente feito e totalmente organizado. É traçar o próprio caminho na resistência do sistema social com operações quase invisíveis e quase inomináveis. Um último aspecto, enfim, é ético: a prática cotidiana restaura com paciência e tenacidade um espaço de jogo, um intervalo de liberdade, uma resistência à imposição (de um modelo, de um sistema ou de uma ordem): poder fazer é tomar a própria distância, defender a autonomia de algo próprio (CERTEAU, 2013, p. 339-340).

Tanto nas artes de morar e cozinhar, quanto nas artes de ensinar, há que se atentar, enfim, para estes prismas na construção de uma compreensão do campo de ação da operatividade dos praticantes. Sob hábitos banais tem-se tentativas de transformação, bem como de reprodução, relações de poder e de resistência, de regulação e de modulação, que organizam e reorganizam a convivialidade a partir dos interesses, conflitantes ou comuns, de docentes e discentes. Entender estas operações é um meio de apreender os processos cognitivos, mas não apenas estes, de aprendizados realizados à maneira da cultura escolar, embora possam se expressar de modo parcial e fragmentado, até não integralmente consciente, em um quebra-cabeças de comportamentos, discursos e tradições escolares.

\section{CONSIDERAÇÕES FINAIS}

Uma última questão trazida à reflexão, para não concluir: essa aparente contradição entre a mobilização racional de conhecimentos teóricos no ensino de geografias, adquiridos a partir de uma longa formação universitária (quem sabe, matriz daquela estrutura física que fala a matéria, mencionada acima), e as práticas intuitivas urgentes, ordinárias e inventivas dos professores em seus cotidianos de trabalho. A psicologia cognitiva e social, bem ao seu modo estratégico, vem elaborando uma tentativa de explicação que procura enfrentar a questão a partir do duplo funcionamento da mente humana, ou de um funcionamento a duas velocidades, rápido e devagar. Segundo Kahneman (2012), nas decisões do dia a dia não acionamos o pensamento lento, lógico, deliberativo e trabalhoso, apropriado a tarefas que demandam concentração e autocontrole, sem primeiro esgotar um vasto repertório de alternativas de um pensamento rápido, intuitivo e emocional, adequado sobretudo a atividades cognitivas automáticas e involuntárias. 
No caso da docência, uma profissão cujo trabalho é interativo e contextualizado, envolvendo o outro de forma convivial, mas sistemática e permanente (TARDIF, 2005), ao mesmo tempo em que depende daquela base teórica longamente adquirida na universidade, as relações entre ambas são complexas. Mobilizam um vocabulário ao mesmo tempo especializado, de quem precisa tomar decisões pedagógicas justificadas, mas de uso corrente, nos contatos da comunicação cotidiana, diante da necessidade de agir na urgência e decidir na incerteza (PERRENOUD, 2001). Nessa perspectiva, as inventividades docentes funcionam como uma espécie de pensamento intuitivo especializado para o qual

a situação forneceu um indício; esse indício deu ao especialista acesso à informação armazenada em sua memória, e a informação fornece a resposta. A intuição não é nada mais, nada menos que reconhecimento (SIMON apud KAHNEMAN, 2012, p. 20).

Ainda que a categoria do reconhecimento tenha alguma importância para a compreensão das práticas ordinárias e das inventividades docentes, o modo como os professores foram considerados neste texto não nos permite reduzi-los a mentes que vibram entre dois tempos, numa abordagem certamente insuficiente quando se trata de dar conta da criatividade, da oralidade e da operatividade, na perspectiva dos próprios praticantes. Ao ver e ouvir os professores, acompanhando o modo pelo qual eles performatizam suas histórias, talvez estejamos mais próximos de uma função empática das narrativas, que aproxima subjetividades distintas, "não meramente para as observarmos e examinarmos, mas para lhes dar sentido e para enxergarmos o mundo a partir de suas perspectivas" (RITIVOI, 2018, p. 11).

De fato, trata-se de algo mais do que apenas curiosidade acadêmica o que nos mobiliza nesta reflexão, talvez de um "sentimento de companheirismo", de empatia, de uma compreensão narrativa da presença dos outros.

\section{REFERÊNCIAS}

ALENCAR, E. M. L. S. O contexto educacional e sua influência na criatividade. In: Linhas Críticas, v. 8. Brasília (DF), 2002. p. 165-178.

CERTEAU, M. de. A invenção do cotidiano: 1. Artes do fazer. $3^{\mathrm{a}}$ ed., Petrópolis (RJ): Vozes, 1998.

CERTEAU, M. de; GIARD, L.; MAYOL, P. A invenção do cotidiano: 2. Morar, cozinhar. 12a ed., Petrópolis (RJ): Vozes, 2013. 
COPATTI, C. O ensino de Geografia na contemporaneidade e a prática docente para o despertar da criatividade. In: Revista Espaço e Geografia, v. 20. Brasília (DF): UnB, 2017. p. 45-67.

GALLO, S. Deleuze e a educação. Belo Horizonte (MG): Autentica, 2017.

KAHNEMAN, D. Rápido e devagar: duas formas de pensar. Rio de Janeiro (RJ): Objetiva, 2012. $612 \mathrm{p}$.

MATTOS, I. R. de. "Mas não somente assim!" Leitores, autores, aulas como texto e o ensinoaprendizagem de História. In: Tempo [online], v. 11, $\mathrm{n}^{\mathrm{o}}$ 21. Niterói (RJ): Instituto de História UFF, 2006. p. 5-16. ISSN 1980-542X. Disponível em https://doi.org/10.1590/S141377042006000200002.

NAKANO, T. C. Investigando a criatividade junto a professores: pesquisas brasileiras. In: Psicologia Escolar e Educacional, v. 13 (Impresso), 2009. p. 45-53.

NÓVOA, A. Firmar a posição como professor, afirmar a profissão docente. In: Cadernos de Pesquisa, v. 47, nº 166. São Paulo (SP): Fundação Carlos Chagas, out/dez 2017. p. 1106-1133.

OLIVEIRA, I. B. Certeau e as artes de fazer: as noções de uso, tática e trajetória na pesquisa em educação. In: OLIVEIRA, I. B. e ALVES, N. (Orgs.). Pesquisa no/do cotidiano das escolas: sobre redes de saberes. Rio de Janeiro (RJ): DP\&A, 2001.

OLIVEIRA JR. Geografias menores: potências de expressão entre imagens, pesquisa e educação. In: Revista Brasileira de Educação em Geografia, v. 9, no 17. Campinas (SP):jan./jun. 2019. p. 27-43.

PERRENOUD, P. Ensinar: agir na urgência, decidir na incerteza. $2^{\mathrm{a}}$ ed., Porto Alegre (RS): Artmed, 2001. 208 p.

RITIVOI, A. D. Empatia, intersubjetividade e compreensão narrativa: lendo as histórias, lendo as vidas (dos outros). São Paulo (SP): Letra e Voz, 2018. 72 p.

SARLO, B. Cenas da vida pós-moderna: intelectuais, arte e videocultura na Argentina. $5^{\mathrm{a}}$ ed., Rio de Janeiro (RJ): Editora UFRJ, 2013. 244 p.

SELLES, S. E.; ANDRADE, E. P. Políticas Curriculares e subalternização do trabalho docente. In: Educação em Foco, v. 21. Juiz de Fora (MG): 2016. p. 39-64.

TARDIF, M.; LESSARD, C. O trabalho docente: elementos para uma teoria da docência como profissão de interações humanas. Petrópolis (RJ): Vozes, 2005. 320 p.

TAVARES, F. G. O. O conceito de inovação em educação: uma revisão necessária. In: Educação, v. 44 (online). Santa Maria (RS): UFSM, 2019. p. 4, 2019.

ZANATTA, B. A. As referências teóricas da geografia escolar e sua presença na investigação sobre as práticas de ensino. Revista Educativa, v. 13, nº 2. Goiânia (GO): jul./dez. 2010. p. 285-305.

ZUMTHOR, P. Performance, recepção, leitura. São Paulo (SP): Cosac Naify, 2014. 